\title{
CORRECTION
}

\section{Correction to: Chatbots to Support Mental Wellbeing of People Living in Rural Areas: Can User Groups Contribute to Co-design?}

\author{
C. Potts ${ }^{1} \cdot$ E. Ennis ${ }^{2} \cdot$ R. B. Bond ${ }^{1}$ - M. D. Mulvenna ${ }^{1} \cdot$ M. F. McTear $^{1} \cdot$ K. Boyd ${ }^{3} \cdot$ T. Broderick $^{4} \cdot$ M. Malcolm $^{5}$.

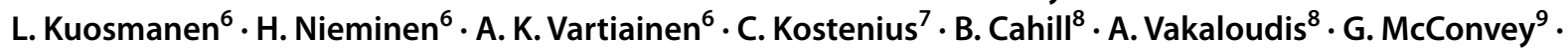 \\ S. O'Neill ${ }^{2}$
}

Published online: 2 October 2021

(c) Springer Nature Switzerland AG 2021

\section{Correction to: Journal of Technology in Behavioral Science https://doi.org/10.1007/s41347-021-00222-6}

The original version of this article unfortunately contained a mistake. The name of the author M.D. Mulvenna is now corrected in the author group.

The original article has been corrected.
Publisher's Note Springer Nature remains neutral with regard to jurisdictional claims in published maps and institutional affiliations.

The original article can be found online at https://doi.org/10.1007/ s41347-021-00222-6.

\section{Potts}

c.potts@ulster.ac.uk

1 School of Computing, Ulster University, Newtownabbey, UK

2 School of Psychology, Ulster University, Derry-Londonderry, UK

3 School of Art, Ulster University, Belfast, UK

4 Department of Sport, Leisure and Childhood Studies, Munster Technological University, Cork, Ireland

5 NHS Western Isles, Stornoway, UK

6 Department of Nursing Science, University of Eastern Finland, Kuopio, Finland

7 Department of Health Sciences, Luleå University of Technology, Luleå, Sweden

8 Nimbus Research Centre, Munster Technological University, Cork, Ireland

9 Action Mental Health, Newtownards, UK 